\title{
Influencing Factors of Background Music Application in Tourist Attractions Based on DEMATEL
}

\author{
Ping Zhao \\ Gingko College of Hospitality Management, Chengdu, China
}

\begin{abstract}
This paper reveals the influencing factors of background music application in tourist attractions from three dimensions of music selection, application management and supporting services. Using DEMATEL model to analyze the interaction between the various factors and the degree of affect and importance according to the calculation results. With consideration of the key factors of performance activities, lighting, various style, particularmusicartisticconceptionand regional cultural characteristics, this paper puts forward some suggestions on application of background music in A-level tourist attractions.
\end{abstract}

Keywords: Affect degree, Key factors, Background music, Tourist attraction, DEMATEL

\section{Introduction}

The development of A-level tourist attractions is boost in Chengdu, China. As of March 2020, there are 91 A-level tourist attractions in Chengdu. They are 1 Class 5A, 47 Class 4A, 28 Class 3A, 14 Class 2A and 1 Class 1A tourist attractions. Although the impact of COVID-19 remains, people pay more attention to the tourist experience with elimination of mental fatigue and the enjoyment of psychological aesthetics. The A-level tourist attractions will face the challenge of providing experience scenes. Background music is an important auditory experience product in tourist attractions. To fully tap the potential value of background music is a feasible way to build the scenic area into a static experience space. At present, the A-level tourist attractions in Chengdu generally lack of attention to the application of background music, the tourists' perception of background music is poor and the effect of background music on tourist attractions is limited. This paper establishes an index that affects tourists' perception of the background music in tourist attractions, quantitatively analyzes the influence relationship and degree of each factor, identifies the key factors, and takes targeted countermeasures, so as to provide reference for an effective application of background music in A-level tourist attractions.

\section{Literature Review}

\subsection{Environmental music}

From the function and purpose of music, background music is equivalent to environmental music. The concept of environmental music was put forward in 1960s. Western scholars mainly study the effect of environmental music ${ }^{[1]}$, the industrial field of music application, etc. The research of environmental music in China starting from the function of accompaniment or soundtrack, pay attention to the effect in games, films, stage plays or hotels, restaurants, shopping malls, office buildings, etc.

\subsection{Background music in tourist attractions}

There is few research particularly on the background music of tourist attractions in western countries. Domestic research on background music of tourist attractions includes selection and application of background music of tourist facilities. In the selection of background music, there are few research results at present, all of which are the operation level of music or song playing ${ }^{[2,3]}$, without studying the relationship of background music with the tourist attractions. In the application of background music in tourist facilities, the research are mainly focused on

ISSN: 0010-8189

(C) CONVERTER 2021

www.converter-magazine.info 
the background music of hotels ${ }^{[4,5]}$ and tea performances ${ }^{[6-8]}$.

\section{Methodology}

\subsection{Study areas selected}

In the selection of study areas, it follows the typical sampling logic and adopts the typical case sampling method. The proportion of Class 4A and 3A tourist attractions is relatively highin Chengdu. Therefore, six Class 4A and six Class $3 \mathrm{~A}$ tourist attractions are selected for questionnaire, including four newly assessed tourist attractions that year. Later, when survey the management and service of background music in tourist attractions of Pidu District, the more advantageous types of tourist attractions are mainly considered. Wangcong Temple (4A, features historical culture), Nongke Village (4A, features rural recreation), Sichuan Cuisine Museum (3A, features cultural experience) and Shuguo Azalea Capital (2A, features agriculture) are selected for the survey.

\subsection{Questionnaire}

The questionnaire is designed into three parts. The first part is the basic information of the respondents consist of gender, age, education level, etc. The second is the tourists' perception of background music in A-level tourist attractions. The third is the influencing factors of the application of background music in tourist attractions. During the May Day holiday in 2018, a total of 300 questionnaires were sent out and 248 valid questionnaires were recovered, with an effective rate of $82.7 \%$.

\subsection{Interview}

The key figures were selected from different groups, including management company and tourism administration department. The semi-structured interview method is used to obtain their attitude towards the management and service of background music in tourist attractions, which can better fill the problem of incomplete data in the previous questionnaire. The content involves the specific application of background music in tourist attractions, such as playing mode, track selection, instrumental music types, copyright acquisition, technical equipment and so on.

\section{Results}

\subsection{The perception of music}

In the investigation on the effect of background music, $62 \%$ of the tourists did not notice that there was background music, and the feeling of background music was poor. The tourists were generally dissatisfied with the volume, rhythm and circulation of background music. The main reason is that the environment of the tourist attractions is relatively complex, especially the rural tourism scenic area has a long tour line, and the background music playing system is lagging behind, the playing volume and decibel measurement are unstable. At the meantime, $74.2 \%$ of the tourists think that the music at the entrance of the scenic spot can arouse the excitement of tourists entering the scenic spot, leave a deep first impression on the tourists, and play a better role in rendering the atmosphere. $67.5 \%$ of tourists said that background music can complement tourism activities when they visit scenic spots, play entertainment and participate in experience projects, and $44.6 \%$ of them also said that background music affects the tourism or entertainment. $82 \%$ of the tourists said that when they consume in restaurants and shopping spots, they are not impressed by the background music, but feel that the music atmosphere will improve the pleasure level of catering and shopping.

The investigation found that the design and application of background music in tourist attractions is still blank. It is often simply understood as music playing. The choice of repertoire is more casual, and most of them are pop music. They mainly use the broadcasting system, and basically use the free copyright music from website. The tourists think that the matching degree between the background music and the environment is low, which even affects the

ISSN: 0010-8189 
tourism activities, mainly due to improper music selection and repeated playing.

4.2. The influencing factors of background music application

4.2.1 Construction of index system of influencing factors

Referring to the relevant contents of tourism products and format standards in the Table of Tourism Industry Standard System, 3 rule layers and 12 index layers of background music selection, application management and supporting services are selected as the main factors affecting the perception of background music in tourist attractions.

Table 1 Index system of influencing factors

\begin{tabular}{|c|c|c|}
\hline Rule layer & Index layer & Symbol \\
\hline Music selection & Rich in variety & $\mathrm{X}_{1}$ \\
\cline { 2 - 3 } & Personalized repertoire & $\mathrm{X}_{2}$ \\
\cline { 2 - 3 } & Various style & $\mathrm{X}_{3}$ \\
\cline { 2 - 3 } & Sharp image & $\mathrm{X}_{4}$ \\
\hline \multirow{3}{*}{$\begin{array}{c}\text { Application } \\
\text { management }\end{array}$} & Appropriate volume & $\mathrm{X}_{5}$ \\
\cline { 2 - 3 } & Loop playback & $\mathrm{X}_{6}$ \\
\cline { 2 - 3 } & Particular music artistic conception & $\mathrm{X}_{7}$ \\
\cline { 2 - 3 } & Regional cultural characteristics & $\mathrm{X}_{8}$ \\
\cline { 2 - 3 } & Intelligent management & $\mathrm{X}_{9}$ \\
\hline Supporting \\
services & Perfect equipment and facilities & $\mathrm{X}_{10}$ \\
\cline { 2 - 3 } & Lighting & $\mathrm{X}_{11}$ \\
\cline { 2 - 3 } & Performance activities & $\mathrm{X}_{12}$ \\
\hline
\end{tabular}

4.2.2 Analysis of influence relationship among factors

There are many factors that affect the application system of background music in tourist attractions, and the relationship among them is complex and the degree of influence is uncertain. As a result, a comprehensive analysis method should be selected to simplify the process of system structure analysis and select the key factors from the complex elements. Therefore, the DEMATEL model is used to solve the complex and multi factor influence of background music application system in A-level scenic spots in Chengdu. Firstly, the expert experience and knowledge are used to make the initial judgment of the influencing factors, and then the structural correlation among the influencing factors of the system is further identified through matrix operation. The steps are as follows: (1) Suppose that the influencing factors of background music application in scenic spots are $X_{1}, X_{2}, \ldots, X_{n}$ (Table 1). (2) Analyze the influence relationship among the factors. If there is an influence relationship between the two factors, the arrow line is used to connect them. The degree of mutual influence is divided into five levels: no influence (0), very weak influence (1), strong influence (2), average influence (3), strong influence (4) and very strong influence (5).

(3) According to the experts' scores, the direct influence matrix of the application of background music in scenic spots is obtained, which is 12 order matrix $\mathrm{X}=\left(\mathrm{X}_{\mathrm{ij}}\right)_{12} \times 12$

ISSN: 0010-8189 


$\mathrm{X}=\left[\begin{array}{cccccccccccc}0 & 0.89 & 4.76 & 1.95 & 0 & 0.75 & 2.06 & 1.56 & 4.23 & 0 & 0 & 3.67 \\ 3.14 & 0 & 0.44 & 4.35 & 0 & 0.36 & 3.17 & 4.07 & 3.35 & 2.46 & 3.89 & 4.53 \\ 4.26 & 2.76 & 0 & 2.78 & 0 & 3.55 & 4.66 & 2.67 & 3.77 & 0 & 4.26 & 4.78 \\ 1.79 & 3.81 & 0.34 & 0 & 3.49 & 3.69 & 4.25 & 4.58 & 0.57 & 2.67 & 4.66 & 4.05 \\ 2.54 & 1.22 & 1.79 & 0.87 & 0 & 4.35 & 3.04 & 1.47 & 3.67 & 1.23 & 3.68 & 4.46 \\ 1.12 & 0 & 2.23 & 2.36 & 4.27 & 0 & 0.67 & 3.13 & 1.87 & 4.02 & 1.54 & 0.67 \\ 2.45 & 2.04 & 3.76 & 1.88 & 0 & 0 & 0 & 4.56 & 0 & 3.89 & 4.55 & 3.21 \\ 2.59 & 2.68 & 3.88 & 0.45 & 0 & 2.68 & 3.66 & 0 & 0 & 3.26 & 4.34 & 4.68 \\ 0 & 0 & 2.14 & 0 & 3.45 & 4.36 & 3.01 & 0 & 0 & 3.01 & 2.24 & 3.89 \\ 0 & 0 & 0 & 0 & 4.65 & 3.89 & 3.23 & 0 & 4.74 & 0 & 3.78 & 3.54 \\ 0.58 & 1.48 & 1.67 & 3.26 & 3.68 & 2.33 & 3.76 & 3.27 & 3.67 & 1.24 & 0 & 2.47 \\ 0 & 3.42 & 3.49 & 2.69 & 3.55 & 1.06 & 0.23 & 2.86 & 1.57 & 2.01 & 1.24 & 0\end{array}\right]$

(4) Normalize the direct influence matrix and get the matrix $G=(\mathrm{Gij})_{12} \times 12$

\begin{tabular}{|c|c|c|c|c|c|c|c|c|c|c|c|}
\hline 0 & 0.0223 & 0.1191 & 0.0489 & 0 & 0.0188 & 0.0516 & 0.039 & 0.1059 & 0 & 0 & 0.0919 \\
\hline 0.0786 & 0 & 0.011 & 0.1089 & 0 & 0.009 & 0.0793 & 0.1019 & 0.0839 & 0.0616 & 0.0974 & 0.1134 \\
\hline 0.1066 & 0.0691 & 0 & 0.0696 & 0 & 0.0889 & 0.1166 & 0.0668 & 0.0944 & 0 & 0.1066 & 0.1197 \\
\hline 0.0448 & 0.0954 & 0.0085 & 0 & 0.0874 & 0.0901 & 0.1064 & 0.1146 & 0.0143 & 0.0669 & 0.1166 & 0.1014 \\
\hline 0.028 & 0 & 0.0558 & 0.0591 & 0.1069 & 0 & 0.0168 & 0.0783 & 0.0468 & 0.1006 & 0.0385 & 0.0168 \\
\hline 0.0613 & 0.0511 & 0.0941 & 0.0471 & 0 & 0 & 0 & 0.1141 & 0 & 0.0974 & 0.1139 & 0.0804 \\
\hline 0.0648 & 0.0671 & 0.0971 & 0.0113 & 0 & 0.0671 & 0.0916 & 0 & 0 & 0.0816 & 0.1086 & 0.1172 \\
\hline 0.0145 & 0.037 & 0.0418 & 0.0816 & 0.0921 & 0.0583 & 0.0841 & 0.0819 & 0.0919 & 0.031 & 0 & 0.0618 \\
\hline 0 & 0.0856 & 0.0874 & 0.0673 & 0.0889 & 0.0265 & 0.0058 & 0.0716 & 0.0393 & 0.0503 & 0.031 & 0 \\
\hline
\end{tabular}

ISSN: 0010-8189 
(5) $\mathrm{T}=\mathrm{g}(1-\mathrm{g})-1$, calculate the comprehensive influence matrix $\mathrm{T}=\left(\mathrm{T}_{\mathrm{ij}}\right)_{12} \times_{12}$, and analyze the indirect influence relationship between various factors.

$\mathrm{T}=\left[\begin{array}{ccccccccccccc}0 & 0.0228 & 0.1352 & 0.0514 & 0 & 0.0192 & 0.0544 & 0.0406 & 0.1184 & 0 & 0 & 0.1012 \\ 0.0853 & 0 & 0.0111 & 0.1222 & 0 & 0.0091 & 0.0861 & 0.1135 & 0.0916 & 0.0656 & 0.1079 & 0.1279 \\ 0.1193 & 0.0742 & 0 & 0.0748 & 0 & 0.0976 & 0.1320 & 0.0716 & 0.1042 & 0 & 0.1193 & 0.1360 \\ 0.0469 & 0.1055 & 0.0086 & 0 & 0.0958 & 0.0990 & 0.1191 & 0.1294 & 0.0145 & 0.0717 & 0.1320 & 0.1128 \\ 0.0679 & 0.0315 & 0.0469 & 0.0223 & 0 & 0.1222 & 0.0824 & 0.0382 & 0.1012 & 0.0318 & 0.1014 & 0.1317 \\ 0.0288 & 0 & 0.0591 & 0.0628 & 0.1197 & 0 & 0.0171 & 0.0850 & 0.0491 & 0.1119 & 0.0400 & 0.0171 \\ 0.0653 & 0.0539 & 0.1039 & 0.0494 & 0 & 0 & 0 & 0.1288 & 0 & 0.1052 & 0.1285 & 0.0874 \\ 0.0693 & 0.0719 & 0.1075 & 0.0114 & 0 & 0.0719 & 0.1008 & 0 & 0 & 0.0889 & 0.1218 & 0.1328 \\ 0 & 0 & 0.0566 & 0 & 0.0946 & 0.0112 & 0.0812 & 0 & 0 & 0.0814 & 0.0594 & 0.1079 \\ 0 & 0 & 0 & 0 & 0.1317 & 0.1079 & 0.0880 & 0 & 0.1346 & 0 & 0.1045 & 0.0972 \\ 0.0147 & 0.0384 & 0.0436 & 0.0889 & 0.1014 & 0.0619 & 0.0918 & 0.0892 & 0.1012 & 0.0320 & 0 & 0.0659 \\ 0 & 0.0936 & 0.0958 & 0.0719 & 0.0976 & 0.0272 & 0.0058 & 0.0771 & 0.0409 & 0.0530 & 0.0320 & 0\end{array}\right]$

(6) Explore the influencing factors. According to the element $T_{\mathrm{ij}}$ in the comprehensive influence matrix, the affect degree $D_{i}$, the affected degree $R_{j}$, the center degree $M_{i}$ and the cause degree $H_{i}$ are calculated.

Table 2 Comprehensive impact relationships

\begin{tabular}{|c|c|c|c|c|}
\hline Factors & $\begin{array}{c}\text { Affect degree } \\
\left(\mathrm{D}_{\mathrm{i}}\right)\end{array}$ & $\begin{array}{c}\text { Affected degree } \\
\left(\mathrm{R}_{\mathrm{j}}\right)\end{array}$ & $\begin{array}{c}\text { Center degree } \\
\left(\mathrm{M}_{\mathrm{i}}\right)\end{array}$ & $\begin{array}{c}\text { Cause degree } \\
\left(\mathrm{H}_{\mathrm{i}}\right)\end{array}$ \\
\hline $\mathrm{X}_{1}$ & 0.5432 & 0.4975 & 1.0407 & 0.0457 \\
\hline $\mathrm{X}_{2}$ & 0.8203 & 0.4918 & 1.3121 & 0.3285 \\
\hline $\mathrm{X}_{3}$ & 0.929 & 0.6683 & 1.5973 & 0.2607 \\
\hline $\mathrm{X}_{4}$ & 0.9353 & 0.5551 & 1.4904 & 0.3802 \\
\hline $\mathrm{X}_{5}$ & 0.7775 & 0.6408 & 1.4183 & 0.1367 \\
\hline $\mathrm{X}_{6}$ & 0.5906 & 0.6272 & 1.2178 & -0.0366 \\
\hline $\mathrm{X}_{7}$ & 0.7224 & 0.8587 & 1.5811 & -0.1363 \\
\hline $\mathrm{X}_{8}$ & 0.7763 & 0.7734 & 1.5497 & 0.0029 \\
\hline $\mathrm{X}_{9}$ & 0.4923 & 0.7557 & 1.2480 & -0.2634 \\
\hline $\mathrm{X}_{10}$ & 0.6639 & 0.6415 & 1.3054 & 0.0224 \\
\hline $\mathrm{X}_{11}$ & 0.729 & 0.9468 & 1.6758 & -0.2178 \\
\hline $\mathrm{X}_{12}$ & 0.5949 & 1.1179 & 1.7128 & -0.5230 \\
\hline
\end{tabular}

Factors with a cause degree greater than zero are called causal factors which has a great influence on other factors. It is robust and difficult to change thus it must be given priority. It can be seen from table 2 that factors such as sharp image $\left(\mathrm{X}_{4}\right)$, personalized repertoire $\left(\mathrm{X}_{2}\right)$, Various style $\left(\mathrm{X}_{3}\right)$ and appropriate volume $\left(\mathrm{X}_{5}\right)$ are more than zero, and the numerical order is higher, which are the factors influencing the application of background music in tourist attractions. Background music is the most dominant source of information in tourist attractions besides landscape. Reasonable selection and scientific use of background music directly affect the formation of personalized style in tourist attractions. It is well known that more than $70 \%$ of the information people get comes from vision, more than

ISSN: 0010-8189

C CONVERTER 2021

www.converter-magazine.info 
$20 \%$ from hearing, and some from other aspects. Appropriate background music can not only set off the theme of tourism products and make tourists happy, but also make them fully integrate into the aesthetic space of scenic spots. On the contrary, it will hinder the expression of the theme image of scenic spots and affect the emotions, feelings and mood of tourists, thus affecting the brand perception of tourist attractions. In the space production of tourist attractions, tourism service environment is the basic construction content. Tourism service environment includes decoration, temperature, light, sound and other elements, among which background music plays a very important role. Especially in the current popular immersive and scene style experience projects, performance activities and background music featured with personalized repertoire, distinct theme image, and diversified jointly represent the style and temperament of the tourism project. Tourists will unconsciously combine the listening experience brought by the background music with the overall taste of the tourism situation.

The factor with negative cause degree is the result factor, which is easily affected by other factors. It can be seen from table 2 that the factors with larger absolute value in the result factors are performance activities $\left(\mathrm{X}_{12}\right)$, Intelligent management $\left(\mathrm{X}_{9}\right)$, lighting $\left(\mathrm{X}_{11}\right)$, particular music artistic conception $\left(\mathrm{X}_{7}\right)$. The aesthetic and entertainment function of art activities mainly refers to that people can adjust their body and mind and get pleasure in their spirit in the aesthetic activities of art( Wang, 2010) ${ }^{[9]}$. Both music and tourism are aesthetic activities that produce perception and cognition to beautiful things, which can meet people's spiritual needs. They have both artistic commonness and complementary function to artistic conception. Of course, background music is an assistant of tourism activities, and its existence is based on the visual experience of landscape. Background music can use its pitch, rhythm change, rhythm speed, etc. to achieve the best influence of tourism aesthetics.

Centrality is the key factor that affects the design of background music application system in scenic spots. Table 2 shows that performance activities $\left(\mathrm{X}_{12}\right)$, lighting $\left(\mathrm{X}_{11}\right)$, various style $\left.\left(\mathrm{X}_{3}\right)\right)$, particular music artistic conception $\left(\mathrm{X}_{7}\right)$ and regional cultural characteristics $\left(\mathrm{X}_{8}\right)$ are the top key factors of centrality, which are concentrated in the level of music playing management and supporting services. In the field of service, atmosphere is an important marketing factor, including background music, lighting, color, smell, and visual effect, which all have a certain impact on consumers' emotions and behaviors. Background music is different from other types of music. It unconsciously stimulates tourists' senses, extends to the auditory, wakes up feelings, perceptions and appearances, produces corresponding emotions, and has a strong influence on tourists' thoughts and feelings. The place where the tourist attraction provides tourism services is a tourism space complex composed of landscapes, gardens and buildings, in which background music is a very active and vitality factor. It can make tourists feel happy and enjoy the tourism services in the alternation of landscape movement and static. In the current era of experience economy, tourist attractions are no longer passive landscape for tourists to watch but actively applying various marketing means to create experience atmosphere and products. Especially, the open tourist attraction will be transformed from a static landscape into a cultural experience space of dynamic and static combination, with particular emphasis on background music, lighting, etc.

\section{V.Discussion and Conclusion}

\subsection{Discussion and implications}

According to the results of Table 2, the affect degree and center degree of the three rule layers of music selection, application management and supporting services are summed. The comprehensive influential relationship is shown in Table 3.

Table 3 Comprehensive influential relationship of rule layers

\begin{tabular}{|c|c|c|}
\hline Rule layer & Affect degree & Center degree \\
\hline Music selection & 2.9272 & 4.9763 \\
\hline Application management & 3.3591 & 7.0149 \\
\hline Supporting services & 1.9878 & 4.6940 \\
\hline
\end{tabular}

ISSN: 0010-8189

(C) CONVERTER 2021 
.It shows that the most affective and central factor of the background music in the scenic area is application management. Music management is the key factor of the design of background music application system in Chengdu tourist attractions, which is in line with the functional definition of background music in the scenic spots. The background music in the scenic spots is environmental music in a broad sense. It refers to the music played in order to create a certain environmental atmosphere in the activities that do not take music as the theme in tourist attractions. It is a kind of music that can make tourists relaxed and happy which can set off and foil the theme and adjust the psychology of the tourists. The design of background music application system in tourist attractions is not the design of music itself, but more attention is paid to the goal of integrating tourism aesthetic audition through selection and combination at the technical and operational level. Music artistic conception is the result of tourists' perception of the background music and the emotional resonance realized by the joint action of hearing and vision. Music has a great influence on modern life, including giving people new productivity and quality of life( Navarro and Pimentel, 2007) ${ }^{[10]}$. The scientific and reasonable application of background music can enable tourists to enjoy a full range of culture and achieve a kind of audio-visual complementary and emotional blending. Tourists involved in the background music are easy to put themselves in the scene, story, felling and other cultural tourism space of the scenic spot to obtain sensory, behavioral, thinking and emotional experience. Therefore, we need to take the following measures to improve the management level of background music in A-level tourist attractions in Chengdu.

\subsubsection{Systematic design}

Firstly, it is the basic work for tourist attractions to plan and design background music system. The background music system shall be incorporated into the public service supporting system of the tourist attraction. In addition to the tourist center and scenic spot, the road, parking lot, tourist toilet, guide system, etc. shall have background music. Secondly, we should design and use background music reasonably. The background music in the tourist attraction is a cultural symbol if the music was suitable, otherwise it will become noise. It is necessary to plan the background music playing system and select music tracks reasonably according to different types of tourist attractions and different functional zoning. Thirdly, It is necessary to care for the tourists with visual impairment. At present, the accessibility design of disabled tourists in the tourist attractions mainly considers disabled people who have no visual barriers, such as special ramps and toilets designed for wheelchair users. But other types of disabilities are seldom considered, such as the tourism needs of visually impaired people. The visually impaired are also an important group of tourists in the tourist attraction. The blind road and the blind logo should be equipped with corresponding background music, so that the blind can fully experience the pleasure of the tour.

\subsubsection{Intelligent management}

With the construction of intelligent tourist attractions, it is the general trend that the modulation signal system consist of fire control, anti-theft alarm system and cable TV, will turn to digital system. Due to the lack of independent program source, the traditional analog background music broadcasting system in tourist attractions can not meet the needs of personalized background music in different functional areas. Chengdu A grade tourist attractions should apply the newest technology in the facilities, equipment and sound effect management of background music, such as the background music system based on IP network. The background music system based on IP network has its own independent sound source and intelligent programming mode. It can solve the problems of short transmission distance, poor sound quality, complex maintenance and management, poor interactive performance and so on.

\subsubsection{Highlight the regional cultural characteristics}

Among A-level tourist attractions in Chengdu, historic culture and rural recreation are the popular. The scenic spots feature historicculture, such as Wuhou Temple, Du Fu Cottage, etc., should study tourists' perception and experience of historical and cultural connotation, and form sound memory through music repertoire and performance techniques from the perspective of aesthetics and humanity. The repertoire is mainly classical music with slow, bright, smooth and rhythmic rhythm. In addition, Chengdu is the birthplace of Chinese farmhouse resorts and has a rich Tianfu farming culture. The rural recreation has developed rapidly in recent years. Therefore, Sichuan native music featured by farming culture is the first choice for background music in the tourist attraction, and traditional musical instruments are used for performance. Sichuan ballad-singing, dulcimer, bamboo

ISSN: 0010-8189 
organ, Money board, Pipa playing and other music tracks with strong Sichuan traditional cultural characteristics are very suitable for selection. With the theme of local cultural elements, Chengdu tourists can enhance their sense of identity and pride, which will also generate attraction and curiosity for overseas visitors. The combination of music elements and guide's interpretation not only embodies the characteristics of the scenic spot, but also conveys feelings and rhymes with sound, so that tourists can experience the long-standing farming culture.

\subsection{Conclusion}

Background music is the most dominant source of information besides landscape, which has the function of enriching tourists' sensory experience. Systematic planning and reasonable design, highlighting the characteristics of regional culture, coordinating with the theme image of the scenic spot, and applying science and technology to improve the sound effect are feasible ways to realize the function and value of background music in A-level tourist attractions of Chengdu.It is necessary to plan the application of background music reasonably according to different types of tourist attractions and different functional zoning. The music should highlight the regional cultural characteristics and form sound memory through music repertoire, so the tourists can experience the longstanding farming culture. The newest technology in the facilities, equipment and sound effect management of background music is available.

\subsection{Limitations of this study and suggestions for future studies}

As the tourist attractions are keen on developing immersive and experiential tourism products, the application of background music involves more complex and emotional relationship between tourists and tourist attractions than before. The interaction of various factors showing a complex, non-linear relationship. DEMATEL and the matrix operation is a linear thinking, it is insufficient in identifying non-linear factors. The weighted influence non-linear gauge system (WINGS)would be considered in the following study, so as to analyze the interconnected components of background music.

\section{Acknowledgements}

This project was supported by Southwest music research center of Sichuan key research base of social sciences expansion (xnyy2018013), Research center for aesthetics and aesthetic education of Sichuan key research base of social sciences (18Y010) and the National social science fund of China (No.19BJY210).

\section{References}

[1] T. Hattori, "Environmental music aesthetics," Translated by Si Youlun, Wang Fengqi, Zhang Fan, etc. China Renmin University Press, 37-38, 1991.

[2] H. Jiang, "Application of red songs in Shaoshan scenic spot," Gehai, no. 2, pp. 66-67+70, 2013.

[3] J. Zhang, "Ingenious use of background music to show the characteristics of rural tourist attractions," Jilin agriculture, no. 11, pp. 131-132, 2015.

[4] Z. Liu, X. Mao, "Creating background music of modern tourist hotel," Journal of Huangshan University, no. 02, pp. 58-60, 2006.

[5] L. Zhuang, "The use of background music in high star hotels and countermeasures," China staff education, no. 22, pp. 134, 2014.

[6] L. Wang, "Selection and application of classical music in tea performance," Fujian tea, no. 2, pp. 102103, 2017.

[7] J. Lu,"Research on background music in Chengdu tea performance," Fujian tea, no.11, pp. 87-88, 2017.

[8] S. Chi, "Promotion of background music on theme content and accumulation of music materials in innovative tea performance," Voice of the Yellow River, vol. 520, no. 19, pp. 121+129, 2018.

[9] H. Wang, "Introduction to art," Culture and Art Press, pp. 59, 2010.

[10] M. P.Navarro, R. L.Pimentel, "Speech interference in food courts of shopping centers," Applied Acoustics, no. 68, pp. 364-375, 2007.

ISSN: 0010-8189 